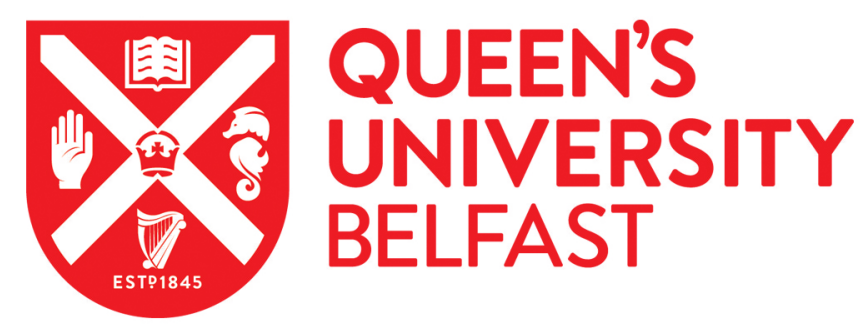

\title{
Statistical modelling of the rheological and mucoadhesive properties of aqueous poly(methylvinylether-co-maleic acid) networks: Redefining biomedical applications and the relationship between viscoelasticity and mucoadhesion
}

Jones, D. S., Lafferty, T. P., Morris, C., \& Andrews, G. P. (2016). Statistical modelling of the rheological and mucoadhesive properties of aqueous poly(methylvinylether-co-maleic acid) networks: Redefining biomedical applications and the relationship between viscoelasticity and mucoadhesion. COLLOIDS AND SURFACES BBIOINTERFACES, 144, 125-134. https://doi.org/10.1016/j.colsurfb.2016.03.008

Published in:

COLLOIDS AND SURFACES B-BIOINTERFACES

Document Version:

Peer reviewed version

Queen's University Belfast - Research Portal:

Link to publication record in Queen's University Belfast Research Portal

Publisher rights

(C) 2016 Elsevier Ltd. This manuscript version is made available under the CC-BY-NC-ND 4.0 license http://creativecommons.org/licenses/bync-nd/4.0/which permits distribution and reproduction for non-commercial purposes, provided the author and source are cited.

\section{General rights}

Copyright for the publications made accessible via the Queen's University Belfast Research Portal is retained by the author(s) and / or other copyright owners and it is a condition of accessing these publications that users recognise and abide by the legal requirements associated with these rights.

Take down policy

The Research Portal is Queen's institutional repository that provides access to Queen's research output. Every effort has been made to ensure that content in the Research Portal does not infringe any person's rights, or applicable UK laws. If you discover content in the Research Portal that you believe breaches copyright or violates any law, please contact openaccess@qub.ac.uk. 
11 "Correspondence: Professor David S. Jones, School of Pharmacy, Queen's

12 University Belfast, Medical Biology Centre, 97, Lisburn Road, Belfast BT9 7BL,

13 United Kingdom

14 Tel: $\quad++442890972011$

15 Fax: $\quad++442890247794$

16 e-mail: d.jones@qub.ac.uk

\section{Statistical Summary}

18 Number of words 5829

19 Number of Figures 4

20 Number of Tables 3 


\section{Abstract}

Poly(methylvinylether-co-maleic acid) (PMVE/MA) is commonly used as a component of pharmaceutical platforms, principally to enhance interactions with biological substrates (mucoadhesion). However, the limited knowledge on the rheological properties of this polymer and their relationships with mucoadhesion has negated the biomedical use of this polymer as a mono-component platform. This study presents a comprehensive study of the rheological properties of aqueous PMVE/MA platforms and defines their relationships with mucoadhesion using multiple regression analysis. Using dilute solution viscometry the intrinsic viscosities of un-neutralised PMVE/MA and PMVE/MA neutralised using $\mathrm{NaOH}$ or TEA were $22.32 \pm 0.89 \mathrm{dL} \mathrm{g}^{-1}, 274.80 \pm 1.94 \mathrm{dL} \mathrm{g}^{-1}$ and $416.49 \pm 2.21 \mathrm{dL} \mathrm{g}^{-1}$ illustrating greater polymer chain expansion following neutralisation using Triethylamine (TEA). PMVE/MA platforms exhibited shear-thinning properties. Increasing polymer concentration increased the consistencies, zero shear rate (ZSR) viscosities (determined from flow rheometry), storage and loss moduli, dynamic viscosities (defined using oscillatory analysis) and mucoadhesive properties, yet decreased the loss tangents of the neutralised polymer platforms. TEA neutralised systems possessed significantly and substantially greater consistencies, ZSR and dynamic viscosities, storage and loss moduli, mucoadhesion and lower loss tangents than their $\mathrm{NaOH}$ counterparts. Multiple regression analysis enabled identification of the dominant role of polymer viscoelasticity on mucoadhesion ( $r>0.98)$. The mucoadhesive properties of PMVE/MA platforms were considerable and were greater than those of other platforms that have successfully been shown to enhance in vivo retention when applied to the oral cavity, indicating a positive role for PMVE/MA mono-component platforms for pharmaceutical and biomedical applications. 


\section{Introduction}

Poly (methylvinylether-co-maleic anhydride) is a 1:1 copolymer of methyl vinyl ether and maleic anhydride that is available in various grades, including the free acid form, poly (methyl vinyl ether-co-maleic acid) (PMVE/MA)[1]. The low toxicity and excellent biocompatibility of PMVE/MA have resulted in its widespread use throughout the pharmaceutical and cosmetic industry[2, 3]. In particular, this polymer has found use within toothpastes, mouthwashes, denture adhesives, hairsprays, transdermal patches, periodontal drug delivery systems and within stoma adhesive pastes[4-8].

PMVE/MA has been reported to form adhesive interactions with mucin-coated epithelial surfaces (termed mucoadhesion)[9-11] and, as a result, has been used as a component of a range of biomedical implants where retention at the site of application is important, e.g. as mucoadhesive nanospheres and microspheres, mucoadhesive buccal tablets, mucoadhesive implants for application to the periodontal pocket and microneedle transdermal systems. In such applications mucoadhesion has been shown to enhance the retention of the implant at the site of application, thereby facilitating controlled drug release and offering site specific mechanical properties[6, 9, 12, 13]. The mucoadhesive properties of PMVE/MA are accredited to its large molecular weight, its favourable chemical functional groups and anionic charge, all of which aid interaction with the mucus layer through polymer mucin interpenetration and the formation of various hydrogen bridges $[9,14$, $70 \quad 15]$ 
The successful pharmaceutical and biomedical applications of PMVE/MA have predominantly required the formation of networks with other polymers, most notably poly(vinylpyrrolidone, PVP). For example in a series of publications, Jones et al. described the formulation of networks of PMVE/MA and PVP that were designed for use as implants within the oral cavity[6,12,13]. In these studies it was shown that the rheological properties of the networks were engineered through modification of both the ratio of PMVE/MA to PVP and polymer concentration. Other studies have described the design of biomedical implants that involve the use of PMVE/MA in association with other polymers. For example, Moreno et al. described the formulation of thermosensitive hydrogels of PMVE/MA and Pluronic F127 that were designed for the controlled release of proteins[16]. Whereas the combined use of PMVE/MA and poloxamer 407 and hydroxypropylcellulose gels designed for the treatment of oropharyngeal cancer has been described[17]. Most recently however Jones et al. highlighted a significant concern regarding the use of interactive polymer networks involving PMVE/MA. The combination of PMVE/MA and poly(vinyl alcohol) produced rheologically structured, mucoadhesive networks. However, upon storage, the viscoelastic and mucoadhesive properties of the networks were observed to significantly and detrimentally change thereby obviating their use as biomedical implants. Conversely, there was no alteration of the rheological properties of mono-polymeric PMVE/MA systems on storage [18]. The use of binary polymeric networks involving PMVE/MA must therefore be treated with extreme caution.

Despite the (growing) number of publications that describe the use of PMVE/MAbased platforms for biomedical applications (particularly for drug delivery applications), there is a paucity of studies that have examined the physicochemical 
properties of PMVE/MA regarding its suitability as a monopolymeric platform for biomedical applications. This oversight is of scientific relevance for two reasons. Firstly, without an understanding of the rheological and mucoadhesive properties of PMVE/MA, the formulation of existing biomedical implants may not be optimal, with detrimental consequences on their clinical usage. Secondly, full understanding and knowledge of the rheological and mucoadhesive properties will offer possibilities for the use of this polymer for an enhanced range of applications, e.g. as pharmaceutical implants, drug delivery applications and as mucoadhesive, viscoelastic implants designed to facilitate cataract removal[19].

Therefore, this study aims to provide a comprehensive description of the rheological properties of PMVE/MA and, for the first time, to specifically statistically examine the relationship of these properties to the mucoadhesive properties. In particular the generated data and the relationships between the various rheological and mucoadhesive properties will be statistically modelled, thereby providing a comprehensive characterisation of the relationship between these parameters. In so doing this study will offer a beneficial insight into the potential biomedical applications of PMVE/MA and of the contribution of physicochemical properties of PMVE/MA to mucoadhesion, an area as yet not fully clarified. 


\section{$118 \quad 2 . \quad$ Materials and Methods}

$119 \quad 2.1 \quad$ Materials

120 Poly(methylvinylether-co-maleic acid, PMVE/MA) (Gantrez ${ }^{\circledR}$ SBF97) with an average 121 molecular weight of approximately 1,200,000 Da was kindly donated by ISP, Surrey,

122 UK. Sodium hydroxide $(\mathrm{NaOH})$ pellets and triethylamine (TEA) were purchased from 123 Sigma Aldrich, Dorset, England. All other chemicals were purchased from BDH Laboratory supplies Dorset, England and were of AnalaR grade, or equivalent quality.

\subsection{Methods}

\subsubsection{Manufacture of Dilute PMVE/MA Solutions}

Stock solutions $(0.2-0.6 \mathrm{~g} / \mathrm{dl})$ of PMVE/MA were prepared by adding the required mass of polymer to an appropriate volume of deionised water $(\mathrm{pH} 5.0-5.2)$. The polymeric solutions (five replicate batches) were subsequently agitated using a mechanical stirrer. Dilution of stock solutions was carried out to obtain the desired concentration, with the final volume being corrected after neutralisation of the relevant systems. Neutralisation of suitable solutions was carried out via the drop wise addition of sodium hydroxide solution $(30 \% \mathrm{w} / \mathrm{w} \mathrm{NaOH})$ or Triethylamine (TEA) until a $\mathrm{pH}$ value of 7.4 was obtained (measured using a Hanna Instruments $\mathrm{pH}$ meter). The solutions examined reflected a range of un-neutralised, TEA and $\mathrm{NaOH}$ neutralised PMVE/MA systems. 
158 where: $\mathrm{k}$ refers to the $\mathrm{U}$-tube multiplication factor and $t$ refers the solution/solvent 159 flow time (sec)

160 From this the relative viscosity $\left(\eta_{\text {rel }}\right)$ was calculated

$161 \quad \eta_{\text {rel }}=\frac{v}{v_{o}}$

162 Where: $v$ and $v_{o}$ refer to the kinematic viscosities of the polymeric solution and the 163 solvent in which the polymer is dispersed, respectively.
Equation 1 
164 The specific viscosity $\left(\eta_{s p}\right)$ is then calculated:

$165 \eta_{s p}=\eta_{\text {rel }}-1$

Equation 3

166 The reduced viscosity $\left(\eta_{\text {red }}\right)$ may be thus expressed as the ratio of the specific 167 viscosity to the concentration:

$168 \quad \eta_{\text {red }}=\frac{\eta_{s p}}{C}$ Equation 4

169 Where $C$ is the concentration of the polymer in $\mathrm{g} / \mathrm{dl}[20]$.

171 U-tubes were chosen so that the efflux time for each solution was always above 200

$172 \mathrm{sec}$ (or 300 seconds for the $\mathrm{O}$ size tube) thus allowing greater accuracy within 173 measured results. The viscometric properties of five replicate solutions were 174 measured in all cases.

176 Calculation of the intrinsic viscosity of each system $[\eta]$ was performed using the 177 Huggin's equation (equation 5) or the equation described by Fuoss and Strauss 178 (equation 6)[21] [22, 23].

$179 \quad \eta_{\text {red }}=\frac{\eta_{s p}}{C}=[\eta]+k^{\prime}[\eta]^{2} C$ Equation 5

180 Where (in addition to the previous descriptions) $\mathrm{C}$ is the polymer concentration and

181 k' refers to Huggin's constant

$182 \quad \eta_{s p}=\frac{[\eta]}{(1+B \sqrt{C})}$ Equation 6

183 Where: $\mathrm{C}$ is the polymer concentration and $\mathrm{B}$ is a constant 
186 Continuous shear (flow) analyses were performed at $37^{\circ} \mathrm{C}$ on the PMVE/MA $(5-30 \%$ $187 \mathrm{w} / \mathrm{w}$ ) systems using a TA systems AR2000 rheometer. Flow rheograms were 188 determined using either a $6 \mathrm{~cm}$ or $4 \mathrm{~cm}$ parallel stainless steel plate (gap size 1000 $189 \mu \mathrm{m})$, the choice of geometry being determined by sample consistency. Samples to 190 be analysed were applied to the lower plate and allowed 15 minutes to equilibrate to 191 negate any stresses induced during sample application. The shear stress was 192 applied over a predetermined range, with this range again being determined by 193 sample consistency. Mathematical modelling of the flow properties of the various 194 polymeric platforms was performed using the Rheology Advantage software (TA 195 Instruments) in conjunction with the Ostwald-de-Waele power law model (equation 196 7)[24] and the Cross model (equation 8)[25], as follows:

$197 \sigma=k \dot{\gamma}^{n}$ Equation 7

198 Where: $\sigma$ refers to the shear stress, $\dot{\gamma}$ refers to the rate of shear, $\mathrm{k}$ refers to the 199 consistency and $\mathrm{n}$ represents a power law index

$200 \quad \eta=\eta_{\infty}+\frac{\eta_{o}-\eta_{\infty}}{1+(K \dot{\gamma})^{m}}$ Equation 8

201 Where: $\eta$ is viscosity, $\eta_{\infty}$ is the infinite shear viscosity, $K$ is a structural relaxation 202 time, $m$ is dimensionless and $\eta_{0}$ is the zero rate viscosity.

203 In each case, the flow properties of at least five replicates were determined.

\subsubsection{Oscillatory Analysis.}

206 Oscillatory analyses were performed at $37^{\circ} \mathrm{C}$ on PMVE/MA $(5-30 \% \mathrm{w} / \mathrm{w})$ systems 207 using a TA systems AR2000 rheometer, as previously reported by the authors[26]. 
208 Rheological analyses were conducted using either a $6 \mathrm{~cm}$ or $4 \mathrm{~cm}$ parallel stainless

209 steel plate (gap size $1000 \mu \mathrm{m}$ ); the choice of geometry was determined by sample

210 consistency. Samples to be analysed were applied to the lower plate and allowed

21115 minutes to equilibrate to negate any stresses induced during sample application.

212 For each sample, the linear viscoelastic region was determined via a stress sweep at

213 a fixed frequency. Once determined, a frequency sweep from 0.1 to $10 \mathrm{~Hz}$ was

214 performed at a stress value selected from within the linear viscoelastic region. The

215 linear viscoelastic region was identified as the region in which the stress and the

216 strain were directly proportional and where the storage modulus $(G)$ remained

217 constant. From the resulting relationships between modulus and oscillatory

218 frequency, the storage modulus (G'), loss modulus (G”), dynamic viscosity ( $\left.\eta^{\prime}\right)$ and

219 the loss tangent (tan $\delta$ ) were then determined using the Rheology Advantage

220 software provided by T.A. Instruments. In each case the dynamic rheological

221 properties of at least five replicates were determined.

\subsubsection{Mucoadhesion Testing}

224 Mucoadhesion testing was conducted using a TA XT2 Texture Analyser in adhesion 225 mode as previously reported by Jones et al.[27-29]. In brief, 400mg mucin discs 226 were manufactured using a $13 \mathrm{~mm}$ IR press using a force of 10 tonnes for a period of 227 one minute. The discs were then attached to the end of a $10 \mathrm{~mm}$ diameter 228 polycarbonate probe via double sided adhesive tape. Samples to be analysed were 229 transferred into a three-sided mould with mucoadhesion testing being determined at $23037^{\circ} \mathrm{C}$. Prior to testing, samples were stored in sealed sample vials incubated at $37^{\circ} \mathrm{C}$ 231 for $24 \mathrm{hrs}$. Before testing, the disc was pre-wetted with $5 \%$ mucin solution with 232 excess being removed via blotting. A downward force of $0.1 \mathrm{~N}$ was applied to the 
polymer platform, held for 30 seconds before being removed at a speed of $10 \mathrm{mms}^{-1}$.

234 Mucoadhesion, determined as the force required to detach the polymer platform 235 from the mucin disc, of each formulation was obtained from five replicates 236 measurements.

\subsubsection{Statistical Analysis}

Statistical modelling was performed using a General Linear Model. The effects of polymer concentration, type of $\mathrm{pH}$ neutralising agent and oscillatory frequency on the viscoelastic properties (storage modulus, loss modulus, tan $\delta$ and dynamic viscosity ( $\left.\eta^{\prime}\right)$ were statistically examined using a two-way repeated measures Analysis of Variance. The effects of polymer concentration and type of $\mathrm{pH}$ neutralising agent on the gel strength, rheological exponent and on crossover frequency were statistically examined using a two-way Analysis of Variance. The effects of neutralising agent on the intrinsic viscosity and critical concentration $\left(C^{*}\right)$ of PMVE/MA was statistically analysed using a one way ANOVA. Post-hoc analysis of individual treatment differences was performed using Tukey's HSD test. In all cases $p<0.05$ was accepted as denoting significance and therefore the individual probability values have not been included in the text.

Statistical modelling of the relationship between polymer concentration and the type of neutralising agent on the viscoelastic parameters (at three defined frequencies, 2.37, 5.39 and $9.99 \mathrm{~Hz}$ ) and on mucoadhesion was performed using a multiple linear

255 regression model (two-way ANOVA). As before, post-hoc analysis of individual 256 treatment differences was performed using Tukey's HSD test $(p<0.05$ denoting 
257 significance). The relationships between viscoelastic properties (G', G', $\tan \delta$ and 258 n') and mucoadhesion were examined using multiple correlation analysis.

260 In all cases measurements and statistical analyses were performed on five replicate 261 samples $(n=5)$. 


\section{Results and Discussion}

265 Mucoadhesive polymers have been extensively used within the pharmaceutical 266 industry, finding use within a wide range of formulations such as eye drops, vaginal 267 gels, nasal inserts, buccal tablets and with some limited success in peroral drug 268 delivery[9]. PMVE/MA has been reported to have strong mucoadhesive properties[8, $2699,30]$ however, this polymer has been limited to a component within implants that 270 contain other polymeric systems. Whilst theoretically this strategy may have merit, 271 the authors have recently reported that PMVE/MA networks may undergo 272 rheological ageing, resulting in compromised rheological and mucoadhesive 273 properties[18]. There are therefore concerns regarding this strategy. There has 274 been a distinct paucity of reports that have examined the mucoadhesive properties 275 and additionally the rheological properties of PMVE/MA monopolymeric systems. 276 Furthermore, this manuscript has addressed a major deficiency in the scientific 277 literature, namely the contribution of polymer viscoelasticity to mucoadhesion, a 278 relationship that requires full understanding to enable the rational design of 279 mucoadhesive systems as biomedical implants.

\subsection{Dilute Solution Properties of PMVE/MA}

282 In this study the intrinsic viscosities of PMVE/MA dilute solutions, (un-neutralised or 283 neutralised using $\mathrm{NaOH}$ or TEA) were determined via extrapolation of the Huggins or 284 the Fuoss and Strauss plots (Figures 1a and 1b, respectively). Modelling of the 285 mathematical relationships revealed that the plot of reduced viscosity against 286 concentration of PMVE/VA for neutralised systems was non-linear thereby 287 invalidating the use of the Huggins model to determine intrinsic viscosity of these 288 systems. Notably, the reduced viscosity was observed to decrease with increasing 
concentration of polymer in a manner typical of polyelectrolyte solutions[31]. Fuoss

290 and Strauss[32, 33] reported an empirical expression from which the intrinsic 291 viscosity of polyelectrolytes may be determined from the linear plot of the reciprocal 292 of reduced viscosity against polymer concentration ${ }^{0.5}$. Using this relationship, the 293 intrinsic viscosities of un-neutralised PMVE/MA and PMVE/MA neutralised using $294 \mathrm{NaOH}$ or TEA were $22.32 \pm 0.89 \mathrm{dL} \mathrm{g}^{-1}, 274.80 \pm 1.94 \mathrm{dL} \mathrm{g}^{-1}$ and $416.49 \pm 2.21 \mathrm{dL} \mathrm{g}^{-}$ 295 1, respectively and were significantly different. Plotting the relationship between $296 \log _{10}$ specific viscosity and $\log _{10}$ polymer concentration provides a further 297 understanding of the dilute solution properties of PMVE/MA. PMVE/MA solutions 298 that had been neutralised using $\mathrm{NaOH}$ or TEA exhibited statistically significant 299 inflection points $\left(C^{*}\right)$ at PMVE/MA concentrations of $0.26 \pm 0.01$ and $0.28 \pm 0.01 \mathrm{~g}$ $300 \mathrm{dl}_{-1}$, respectively. No inflection point was observed for un-neutralised systems. 301 Below the critical overlap concentration $\left(C^{\star}\right)$ within a polymer network, polymer 302 chains exist independently as single units without entanglement. At this dilute 303 concentration, association of polymer chains is negligible allowing analysis of the 304 polymer chain conformation[34]. It is this polymer chain conformation that eventually 305 influences the various topological constraints and supramolecular organisations that 306 will occur within a network eventually giving rise to gel formation[35]. The intrinsic 307 viscosity of a polymer represents the hydrodynamic volume which an individual 308 polymer chain occupies, thereby reflecting the dimensions of the polymer chain[36] 309 and indicates the role of factors, e.g. polymer/solvent interactions, $\mathrm{pH}$ and the 310 presence of other ions within solutions on gel networks formed from these 311 systems[37]. In this study the intrinsic viscosity increased following neutralisation 312 due to the expanded conformation of the polymer chains resultant from ionisation of 313 the pendant carboxyl acid groups of the polymer. Hence, when neutralised the 314 polymer chains are in an expanded conformation occupying a greater spatial 315 dimension than the compact un-neutralised PVME/MA polymer chains. The choice 
316 of neutralising agent was also observed to have a significant effect on the intrinsic

317 viscosity values of PMVM/MA chains. TEA neutralised systems were observed to

318 have significantly higher intrinsic viscosities than those obtained via $\mathrm{NaOH}$

319 neutralisation and hence TEA neutralised chains occupied the greater hydrodynamic

320 volume. Variation between the two neutralised polymeric solutions may be

321 attributed to shielding of these electrostatic charges by sodium ions within solutions

322 neutralised by $\mathrm{NaOH}$, which restricted polymer chain extension. Ionic strength has

323 been shown to have a significant effect on polyelectrolyte gels containing

324 carboxylate groups. Previously Tam and Tiu[38] investigated the effect of various

325 cations on the rheology of solutions of the anionic polymer polyacrylamide. They

326 observed that the presence of cations such as $\mathrm{Na}^{+}$reduced polymer inter and

327 intramolecular interactions causing a significant reduction in solution viscosity.

\subsection{Flow Properties of PMVE/MA Gels}

330 The effects of polymer concentration, neutralisation and the type of neutralising 331 agent on the consistency and rate index of PMVE/MA gels, modelled using the 332 Ostwald-de-Waele power law model and on their zero-shear rate viscosities, 333 modelled using the Cross model, are shown in Table 1. Neutralised polymeric 334 platforms were pseudoplastic, evident from the rate indices being statistically less 335 than 1. Increasing polymer concentration and neutralisation of the PMVE/MA 336 systems significantly decreased the rate index and increased both the consistency 337 and zero-shear rate viscosities. Furthermore, the effect of TEA on these properties 338 was significantly greater than for $\mathrm{NaOH}$. These observations accounted for a 339 statistically significant interaction term in the ANOVA, indicative of a non-additive 340 effect of the various variables. Hence, the effects of polymer concentration on the 
341 aforementioned properties were dependent on the $\mathrm{pH}$ of the gels and the 342 neutralising agent. The observed flow properties of the neutralised gels were 343 expected, given that the polymer concentrations dramatically exceeded the $C^{*}$ 344 concentration. The effect of polymer concentration on the observed flow properties 345 is due to an increased number of molecular interactions between the polymer 346 chains[39]. All platforms showed an increase in the zero rate viscosity (i.e. the 347 viscosity a system would exhibit when at rest) upon increasing polymer 348 concentration, denoting a stronger network due to increased interaction between 349 polymer chains[40]. Increases in zero shear rate viscosity were observed to be non350 linear in relation to increasing PVM/MA concentrations for all platforms; this being 351 indicative of increasing interactions between constituent groups within the polymer 352 chains which are disproportionate to increases in polymer concentration. The 353 effects of neutralisation on the flow properties were in accordance with the 354 observations from dilute solution viscometry, with TEA neutralised systems offering 355 greater resistance to deformation (increased consistency and zero shear rate 356 viscosity) than comparator systems neutralised using $\mathrm{NaOH}$. For example a $25 \%$ 357 w/w TEA neutralised system had a consistency value of $1191.00 \pm 11.53$ Pa.s ${ }^{n}$, and 358 a zero rate viscosity of $3397.67 \pm 80.21 \mathrm{~Pa} . \mathrm{s}$, whilst a $25 \% \mathrm{w} / \mathrm{w} \mathrm{NaOH}$ neutralised 359 system had values of $510.10 \pm 9.20$ Pa.s ${ }^{n}$ and $992.97 \pm 11.22$ Pa.s, respectively. 360 Thus, electrostatic shielding of ionised carboxylate groups due to the presence of $361 \mathrm{Na}^{+}$ions restricts the extension of the PMVE/MA polymer chain within $\mathrm{NaOH}$ 362 neutralised networks. As a result, the more highly expanded PMVE/MA polymer 363 chains, present within TEA neutralised formulations, have a greater probability of 364 entangling with one another thereby forming a more structured network than 365 typically experienced within similarly concentrated $\mathrm{NaOH}$ neutralised formulations. 366 The addition of small counterions can effectively reduce the mutual charge repulsion 367 of carboxylate anions resulting in polymer chain coiling[41]. 


\subsection{Oscillatory Rheometry of PMVE/MA Gels}

370 The effects of frequency, PMVE/MA concentration and type of neutralisation agent 371 on the storage and loss moduli of the systems under investigation are graphically 372 displayed in Figures 2-4. Furthermore, a summary of the effects of the 373 aforementioned parameters on the loss tangents and dynamic viscosities at 374 specified frequencies is presented in Table 2. The frequency dependence of both 375 the elastic and loss moduli indicate that the formation of viscoelastic networks are 376 as a result of non-covalent intermolecular interactions and polymer chain 377 entanglements[42-44]. Whilst increasing PMVE/MA concentration (in the un378 neutralised state) increased the storage and loss moduli and the dynamic viscosity 379 (at each frequency), the magnitudes of these parameters were small and, 380 furthermore, the loss tangent exceeded 1 at all concentrations and frequencies 381 examined. These observations are typical of an elastoviscous system[18]. The 382 failure to determine an LVR for $5 \%$ and $10 \% \mathrm{w} / \mathrm{w}$ PVME/MA un-neutralised 383 formulations can be directly attributed to their lack of suitable viscoelastic structure.

384 These results are consistent with the presence of PMVE/MA in the coiled state, with 385 minimal interactions between adjacent polymer chains[18, 41]. In the neutralised 386 state, the moduli dramatically increased, complementing the findings from 387 continuous shear analysis. The storage and loss moduli and dynamic viscosity 388 exhibited within neutralised systems were significantly higher than those recorded 389 for un-neutralised formulations, whilst $\tan \delta$ values were significantly lower. For 390 example, the storage and loss moduli of a $30 \% \mathrm{w} / \mathrm{w}$ un-neutralised formulation of 391 PVME/MA were $523.03 \pm 25.64 \mathrm{~Pa}$ and $633.20 \pm 26.82 \mathrm{~Pa}$, respectively, whereas

392 the storage and loss moduli of the corresponding $\mathrm{NaOH}$ neutralised system were $3935552.33 \pm 134.75 \mathrm{~Pa}$ and $3310.00 \pm 49.57 \mathrm{~Pa}$ (all measured at a frequency of 6.19 
$394 \mathrm{~Hz}$ ). As observed previously within viscometric and continuous shear analyses, the 395 choice of neutralising agent had a significant effect on measured viscoelastic 396 parameters. TEA neutralised formulations possessed significantly higher elastic and 397 loss moduli and dynamic viscosity values, whereas tan $\delta$ values were observed to 398 be significantly lower than those of $\mathrm{NaOH}$ neutralised systems at comparable 399 PMVE/MA concentrations and oscillatory frequencies. A 30\% PMVE/MA TEA 400 neutralised formulation had a $\tan \delta$ value of $0.50 \pm 0.01$, whereas a $30 \% \mathrm{w} / \mathrm{w}$ $401 \mathrm{PVM} / \mathrm{MA} \mathrm{NaOH}$ neutralised formulation presented a significantly higher $\tan \delta$ value 402 of $0.57 \pm 0.01$ (frequency $8.50 \mathrm{~Hz}$ ). Polyelectrolyte systems are known to be very 403 sensitive to changes in $\mathrm{pH}$, with neutralisation of acidic groups, as observed in this 404 study, leading to the formation of a tighter gel network via non-covalent association 405 of polymer chains[45]. The presence of various ions however can cause shielding of 406 the negatively charged carboxylate groups resulting in a reduction in the repulsion 407 between polymer chains, decreasing formulation viscosity and elasticity[46]. The 408 net effect of this shielding effect that was apparent in this study was gels that had 409 been neutralised by sodium hydroxide exhibited lower elasticity than their organic 410 amine neutralised counterparts. This is apparent from the greater magnitude of the 411 storage modulus, the lower loss tangent values, the lower gel strength and the lower 412 crossover frequency of TEA-neutralised PMVE/MA gels, as depicted in Table 3. 413 This table provides an insight into the frequency dependence of the elastic and loss 414 moduli through the use of a power law model, which characterises the material 415 strength $(K)$ and the frequency dependency of the platform (n). Together, these 416 parameters provide a further understanding of the nature of the platform under 417 investigation[47, 48]. Power Law exponent values of moduli were observed to 418 significantly decrease, whilst moduli gel strength values significantly increased upon 419 increasing PMVE/MA concentration and/or following neutralisation. These observed 420 trends indicate the movement towards more structured viscoelastic networks. An $n$ 
421 value close to or equal to zero is representative of a covalently crosslinked system, 422 whereas a network exhibiting an $\mathrm{n}$ value greater than zero indicates the presence of 423 a physical gel network[36]. All Power Law exponent values were markedly greater 424 than zero, consistent with the properties of polymer-entangled networks. According 425 to Winter and Chambon[49] a power Law exponent for both moduli equal or less 426 than 0.5 and where G'>G", indicates the presence of a gel. Using this principle only 427 a $30 \% \mathrm{w} / \mathrm{w}$ PVME/MA NaOH neutralised system along with $25 \%$ and $30 \% \mathrm{w} / \mathrm{w}$ 428 PVM/MA TEA neutralised systems can be termed gels.

\subsection{Mucoadhesion of PMVE/MA Gels}

431 The effects of polymer concentration and neutralisation/type of neutralising agent on 432 the mucoadhesive properties are presented in Table 3. The mucoadhesive method 433 employed in this study has been frequently reported and is accepted as a model 434 which reliably characterises the interaction between mucin and polymeric 435 platforms $[9,50,51]$. One benefit of this test is the ability to quantify the force (or 436 work) required to break the adhesive bond between the polymer platform and the 437 mucin substrate and therefore the mucoadhesive properties of polymeric platforms 438 may be effectively compared. Polymer concentration and neutralisation/neutraliser 439 type significantly affected mucoadhesion, with a statistical interaction between 440 concentration and neutraliser being identified. In this, the dependency of polymer 441 concentration on mucoadhesion was greater for TEA neutralised systems than for $442 \mathrm{NaOH}$ neutralised systems. The mucoadhesive properties of un-neutralised 443 PMVE/MA systems could not be measured using this technique however, given the 444 ability of the method to reliably measure forces of detachment that are relevant to in 445 vivo retention of dosage forms[29, 52, 53], it may be inferred that the mucoadhesive 
446 properties of these systems are negligible. The mucoadhesive properties of 447 PMVE/MA systems significantly increased with increasing polymer concentration 448 and were greater for TEA-neutralised gels than for their $\mathrm{NaOH}$-neutralised 449 counterparts. The mucoadhesive properties of neutralised PMVE/MA gels (15-30\% $450 \mathrm{w} / \mathrm{w})$ were substantial and greatly exceeded those of mucoadhesive implants that 451 have reported to be successfully retained in vivo within the periodontal pocket[29]. 452 Furthermore, given the wide range of polymer concentrations associated with these 453 enhanced mucoadhesive properties, it is expected that the retention of formulations 454 in vivo, e.g. within the periodontal pocket, would be resistant to dilution from 455 biological fluids. Given both the wide range of concentrations that exhibited 456 mucoadhesive properties and the magnitudes of mucoadhesion exhibited, these 457 mono-polymeric platforms would the expected to offer prolonged retention in vivo. 458 This is the first report that suggests this role for mono-polymeric PMVE/MA 459 platforms.

3.4. Statistical Modelling of the Relationship between Mucoadhesion and Rheological Properties of PMVE/MA Gels

Within this study a series of statistical methods has been employed to ensure that the effects of primary factors on the various rheological properties were fully ascertained within a factorial experimental design. However, importantly, this study additionally examined statistical interactions between the primary factors and 467 explained these within the context of the physicochemical properties of the gel 468 platforms. In so doing, a unique insight into the polymer state was derived. A key 469 task of this manuscript was to understand the relationship between the various 470 polymeric variables and mucoadhesion, a relationship that has not been fully 
471 described in the scientific literature to date. This study therefore described the

472 application of multiple linear regression to model the relationships between the 473 various variables with mucoadhesion, a parameter that is indicative of retention in 474 vivo. Accordingly, using a general linear model three major variables were observed 475 to affect mucoadhesion, namely polymer concentration, $\mathrm{pH}$ and the type of 476 neutralising agent. There were strong statistical interactions between these 477 variables and their effects on mucoadhesion. In these, the effect of polymer 478 concentration on mucoadhesion was significantly greater in gels neutralised with 479 TEA than in gels neutralised using $\mathrm{NaOH}$. Similarly there was an interaction 480 between the $\mathrm{pH}$ and polymer concentration on mucoadhesion in which polymer 481 concentration exhibited a significantly greater effect on the mucoadhesion of 482 PMVE/MA gels when neutralised. To understand these relationships further 483 stepwise multiple regression analysis between the viscoelastic parameters and 484 mucoadhesion was performed. Unsurprisingly, the correlation matrix identified 485 strong relationships between the various viscoelastic properties and therefore the 486 multiple regression analysis was simplified by considering the effect of storage 487 modulus on the mucoadhesive properties of neutralised PMVE/MA platforms over a 488 range of different oscillatory frequencies. At each frequency examined there was a 489 strong relationship between storage modulus and mucoadhesion $(r>0.98)$. 490 Furthermore the relationship between polymer concentration and mucoadhesion 491 was linear ( $r>0.99$ for TEA neutralised gels, $r>0.98$ for $\mathrm{NaOH}$ neutralised gels and 4920.94 for the overall effect combining both types of neutralisation). These results 493 have enabled a re-imagination of the roles of polymer viscoelasticity, concentration 494 and neutralisation on mucoadhesion. The process of mucoadhesion is understood 495 to be complex, with a number of physicochemical properties being reported to 496 contribute to this phenomenon including polymer molecular weight, polymer 497 conformation, degree of cross-linking, the contribution of functional groups on the 

polymer and the charge on these groups[9, 54]. In this study the contribution of polymer molecular weight and the type of functional group were constant across all polymer platforms; however, the contributions of charge on the groups and polymer concentration on mucoadhesion may be considered. Interestingly, there has been little attention paid to the relationships between the aforementioned properties, polymer viscoelasticity and mucoadhesion. This study has addressed this paucity of information. Mucoadhesion involves an adhesive interaction between a polymeric platform and mucin, facilitated through specific (hydrogen) bond formation[9]. In principal, this interaction should be enhanced whenever the functional groups in both polymers are unionised however this study has clearly shown that ionisation, facilitated through neutralisation of the carboxylate groups of PMVE/MA resulted in both marked and enhanced mucoadhesion. Notably, whilst the degree of polymer ionisation affected mucoadhesion, the contribution of polymer viscoelasticity was dominant, as defined within the statistical model. Thus, at identical levels of ionisation the role of neutralising agent on the mucoadhesive and viscoelastic properties was significant. Neutralisation with TEA resulted in a greater expansion of the polymer chains through charge repulsion than in platforms similarly neutralised using $\mathrm{NaOH}$; the difference being accredited to charge shielding of the ionised carboxylate groups with the sodium counterion. At $\mathrm{pH} 7.4$ the degree of ionisation of PMVE/MA was circa $99 \%$ and therefore, whilst there were differences in shielding of charge in the two neutralised, both systems exhibited predominantly anionic properties. With reference to the observed (strong) correlations between polymer viscoelasticity and mucoadhesion, this study has highlighted that the dominant factor that contributes to mucoadhesion is polymer viscoelasticity. Thus, as the elastic properties of PMVE/MA are increased, the mucoadhesion increased, notably in a linear fashion. Whilst not observed in this study, an upper limit in PMVE/MA concentration would be expected beyond which no further increase in 
525 mucoadhesion is observed. In this scenario, the polymer interactions within 526 PMVE/MA would predominate thereby reducing the likelihood of adhesive 527 interactions with mucin. It should be clearly stated that, through the application of 528 statistical modelling, this study has clearly defined the dominant role of polymer 529 viscoelasticity on mucoadhesion, a conclusion that has not been directly defined in 530 previous studies. These observations explain, at least in part, the mucoadhesive 531 properties of non-charged polymers, e.g. cellulose ethers[9].

\subsection{Re-defining the clinical opportunities for PMVE/MA Gels}

Despite the use of PMVE/MA as a component within mucoadhesive platforms, there has been limited use of this polymer as a single component system. Historically, this may be related, at least in part, to the limited viscosity enhancement per unit mass of polymer associated with this polymer (and the associated commercial cost). Alteration of the concentration of PMVE/MA and/or neutralisation enhanced the viscoelastic properties of the polymer platform and, in so doing, facilitated enhanced mucoadhesion. Within the clinical domain, it is important that the

541 administration of implants is both not compromised by viscosity (associated with 542 increased polymer concentration) and is retained at the proposed site of 543 administration, the latter being facilitated by enhanced viscoelasticity (and polymer 544 concentration). Therefore a compromise is required between these two phenomena. 545 There is published evidence that clarifies the key rheological properties of gel 546 systems that have been successfully employed in vivo as implants for the treatment 547 of oral diseases, a potential application for the PMVE/MA systems under current 548 examination[29, 53, 55]. For example in these systems the storage modulus (at 549 circa $10 \mathrm{~Hz}$ ) and zero shear rate viscosity of a platform that was successfully applied 
550 to and retained within the periodontal pocket using a periodontal syringe were circa

$551 \quad 3.5 \mathrm{kPa}$ and 2.6kPa.s, respectively. Accordingly, PVME/MA $30 \% \mathrm{w} / \mathrm{w}$, TEA

552 neutralised gels, despite their excellent mucoadhesive properties would be

553 inappropriate for delivery using a periodontal syringe, however in applications

554 involving application of the gel to the site of action directly from a standard

555 container (e.g. using an applicator or manually), this would not be as important. It

556 should be noted that the rheological and mucoadhesive properties of the polymeric

557 platforms described in this study would be suitable for other pharmaceutical and

558 biomedical applications. For example, modification of the polymer concentration

559 will enable the rheological and mucoadhesive properties of PMVE/MA gels to be

560 engineered that are suitable for use as ophthalmic viscosurgical devices during 561 phacoemulsification[19] or for vaginal drug delivery applications[51]. Finally, it is

562 important to reiterate that by selection of polymer concentration and neutraliser type,

563 PMVE/MA gels may be prepared that offer comparable rheological and

564 mucoadhesive properties to multicomponent polymeric platforms that have been

565 successful clinically $[29,53]$. This is important as it will obviate potential issues with

566 rheological ageing (structuring or destructuring) upon storage of multicomponent 567 systems.

\section{$569 \quad 4 . \quad$ Conclusions}

570 In this study the rheological and mucoadhesive properties of aqueous PMVE/MA

571 platforms have been comprehensively characterised to establish their potential 572 suitability for biomedical and pharmaceutical applications. To address this issue, 573 the contributions of polymer concentration, $\mathrm{pH}$ and type of neutralising agent to the 574 viscoelastic and mucoadhesive properties were statistically modelled. The 
575 application of multiple linear regression analysis enabled the specific relationships

576 between the viscoelastic and mucoadhesive properties to be explicitly defined, a

577 feature that has yet to receive sufficient attention within the scientific literature. This

578 study uniquely identified the dominant contribution of polymer viscoelasticity on

579 mucoadhesion, an outcome that may be employed to rationally design

580 mucoadhesive platforms. Manipulation of both the rheological (flow and oscillatory

581 rheometry) and mucoadhesive properties was performed by changing both polymer

582 concentration and $\mathrm{pH}$ and by choice of neutralising agent. In so doing mono-

583 polymeric PMVE/MA platforms were prepared that, based on previous reports

584 offered wide ranges of rheological and mucoadhesive properties that rendered them

585 suitable for a range of pharmaceutical and biomedical properties where prolonged

586 retention at the site of application is required. 


\section{Legends for Figures}

589 Figure 1a. Huggins plot illustrating the relationship between reduced viscosity 590 and concentration of PMVE/MA. Circles refer to Unneutralised PMVE/MA whereas

591 squares and triangles refer to PMVE/MA that had been neutralised using either $592 \mathrm{NaOH}$ or TEA, respectively. Standard deviations from five replicate measurements 593 are included.

595 Figure 1b. Fuoss and Strauss plot illustrating the relationship between log 596 reduced viscosity and the square root of concentration of PMVE/MA. Circles refer 597 to Unneutralised PMVE/MA whereas squares and triangles refer to PMVE/MA that 598 had been neutralised using either $\mathrm{NaOH}$ or TEA, respectively. Standard deviations 599 from five replicate measurements are included.

601 Figure 2. The relationship between modulus (storage and loss) and frequency 602 for unneutralised PMVE/MA platforms. Figure 2(a) relates to PMVE/MA 5\% w/w 603 (circles), PMVE/MA 10\% w/w (squares) and PMVE/MA 15\% w/w (diamonds). Figure 604 2(b) relates to PMVE/MA 20\% w/w (circles), PMVE/MA 25\% w/w (squares) and 605 PMVE/MA 30\% w/w (diamonds). Closed symbols relate to the storage modulus 606 whereas open symbols refer to the loss modulus. Standard deviations from five 607 replicate measurements are included. 
610 Figure 3. The relationship between modulus (storage and loss) and frequency

611 for PMVE/MA platforms that have been neutralised using $\mathrm{NaOH}$. Figure 3(a) relates

612 to PMVE/MA 5\% w/w (circles), PMVE/MA 10\% w/w (squares) and PMVE/MA 15\%

613 w/w (diamonds). Figure 3(b) relates to PMVE/MA 20\% w/w (circles), PMVE/MA 25\%

$614 \mathrm{w} / \mathrm{w}$ (squares) and PMVE/MA 30\% w/w (diamonds). Closed symbols relate to the

615 storage modulus whereas open symbols refer to the loss modulus. Standard

616 deviations from five replicate measurements are included.

618 Figure 4. The relationship between modulus (storage and loss) and frequency

619 for PMVE/MA platforms that have been neutralised using triethylamine. Figure 4(a)

620 relates to PMVE/MA 5\% w/w (circles), PMVE/MA 10\% w/w (squares) and PMVE/MA

$62115 \% \mathrm{w} / \mathrm{w}$ (diamonds). Figure 4(b) relates to PMVE/MA 20\% w/w (circles), PMVE/MA

$622 \quad 25 \% \mathrm{w} / \mathrm{w}$ (squares) and PMVE/MA 30\% w/w (diamonds). Closed symbols relate to

623 the storage modulus whereas open symbols refer to the loss modulus. Standard

624 deviations from five replicate measurements are included. 
630 [1] G.P. Andrews, J. D.S., Poly(methylvinylether-co-maleic anhydride), in: R.C. Rowe, 631 P.J. Sheskey, P.J. Weller (Eds.) The Handbook of Pharmaceutical Excipients, The 632 Pharmaceutical Press, London, 2009.

633 [2] K. Yoncheva, E. Lizarranga, J.M. Irache, Pegylated nanoparticles based on 634 poly(methyl vinyl ether-co-maleic anhydride): preparation and evaluation of their 635 bioadhesive properties. , European Journal of Pharmaceutical Sciences, 24 (2005) $636 \quad 411-419$.

637 [3] Y. Matsuya, J.M. Antonucci, S. Matsuya, S. Takagi, L.C. Chow, Polymeric 638 calcium phosphate cements derived from poly(methyl vinyl ether-maleic acid). , 639 Dental Materials, 12 (1996) 2-7.

640 [4] P. Arbos, M. Wirth, M.A. Arangoa, F. Gabor, J.M. Irache, Gantrez ${ }^{\circledR}$ AN as a new 641 polymer for the preparation of ligand-nanoparticle conjugates., Journal of Controlled 642 Release, 83 (2002) 321-330.

643 [5] J.A. Martin, T.M. Hughes, N.M. Stone, Peristomal allergic contact dermatitis 644 case report and review of the literature. , Contact Dermatitis, 52 (2005) 273-275.

645 [6] D.S. Jones, M.S. Lawlor, A.D. Woolfson, Formulation and characterisation of 646 tetracycline-containing mucoadhesive polymer networks designed for the treatment 647 of periodontal disease., Current Drug Delivery, 1 (2004) 17 - 25.

648 [7] R.F. Donnelly, P.A. McCarron, M.M. Tunney, A.D. Woolfson, Potential of 649 photodynamic therapy in treatment of fungal infections of the mouth. Design and 650 characterisation of a mucoadhesive patch containing toluidine blue $\mathrm{O}$. , Journal of 651 Photochemistry and Photobiology B. Biology, 86 (2007) 59-69.

652 [8] D.S. Jones, M.S. Lawlor, A.D. Woolfson, Examination of the flow rheological and 653 textural properties of polymer gels composed of poly(methylvinylether-co-maleic 
654 anhydride) and poly(vinylpyrrolidone): Rheological and mathematical interpretation

655 of textural parameters, Journal of Pharmaceutical Sciences, 91 (2002) 2090-2101.

656 [9] G.P. Andrews, T.P. Laverty, D.S. Jones, Mucoadhesive polymeric platforms for

657 controlled drug delivery, European Journal of Pharmaceutics and Biopharmaceutics,

$65871(2009) 505-518$.

659 [10] V.V. Khutoryanskiy, Hydrogen-bonded interpolymer complexes as materials for 660 pharmaceutical applications., Int. J. Pharm., 334 (2007) 15-26.

661 [11] A. Ludwig, The use of mucoadhesive polymers in ocular drug delivery., Adv.

662 Drug Deliv. Rev., 57 (2005) 1595-1639.

663 [12] D.S. Jones, M.S. Lawlor, A.D. Woolfson, Examination of the flow rheological 664 and textural properties of polymer gels composed of poly(methylvinylether-co665 maleic anhydride) and poly(vinylpyrrolidone): Rheological and mathematical 666 interpretation of textural parameters, J. Pharm. Sci., 91 (2002) 2090-2101.

667 [13] D.S. Jones, S. McMeel, C.G. Adair, S.P. Gorman, Characterisation and 668 evaluation of novel surfactant bacterial anti-adherent coatings for endotracheal 669 tubes designed for the prevention of ventilator-associated pneumonia, J. Pharm. 670 Pharmacol., 55 (2003) 43-52.

671 [14] J.M. Gu, J.R. Robinson, S.H. Leung, Binding of acrylic polymers to 672 mucin/epithalial surfaces: Structure-property relationships., Critical Reviews in 673 Terapeutic Drug Carrier Systems, 5 (1988) 21-67.

674 [15] S.H. Leung, J.R. Robinson, The contribution of anionic polymer structural 675 features to mucoadhesion., J. Cont. Rel., 5 (1988) 223-231.

676 [16] E. Moreno, J. Schwartz, E. Larraneta, P.A. Nguewa, C. Sanmartin, M. Agueros, 677 J.M. Irache, S. Espuelas, Thermosensitive hydrogels of poly(methyl vinyl ether-co678 maleic anhydride) - Pluronic (R) F127 copolymers for controlled protein release, Int. 679 J. Pharm., 459 (2014) 1-9. 
680 [17] M. Dhiman, P. Yedurkar, K.K. Sawant, Formulation, characterization, and in 681 vitro evaluation of bioadhesive gels containing 5-fluorouracil, Pharmaceutical 682 Development and Technology, 13 (2008) 15-25.

683 [18] G.P. Andrews, T.P. Laverty, D.S. Jones, Rheological Analysis of Polymer 684 Interactions and Ageing of Poly(Methylvinylether-Co-Maleic Anhydride)/Poly(Vinyl 685 Alcohol) Binary Networks and Their Effects on Mucoadhesion, Journal of 686 Pharmaceutical Sciences, 104 (2015) 4329-4338.

687 [19] G.P. Andrews, S.P. Gorman, D.S. Jones, Rheological characterisation of 688 primary and binary bioadhesive gels composed of cellulose derivatives designed as 689 viscosurgical devices, Biomaterials, 26 (2005) 571-580.

690 [20] S.E. Harding, The intrinsic viscosity of biological macromolecules. Progress in 691 measurement, interpretation and application to structure in dilute solution., Progress 692 in Biophysics and Molecular Biology, 68 (1997) 207-262.

693 [21] F.M. Goycoolea, R.K. Richardson, E.R. Morris, M.J. Gidley, Effect of Locust 694 Bean Gum and Konjac Glucomannan on the conformation and rheology of agarose 695 and kappa-carrageenan., Biopolymers, 36 (1995) 643-658.

696 [22] B. Abbastabar, M.H. Azizi, A. Adnani, S. Abbasi, Determining and modeling 697 rheological characteristics of quince seed gum, Food Hydrocolloids, 43 (2015) 259698264.

699 [23] R.M. Fuoss, U.P. Strauss, Polyelectrolytes. II. Poly-4-vinylpyridonium chloride 700 and poly-4-vinyl-N-n-butylpyridonium bromide. , Journal of Polymer Science, 28 $701 \quad$ (1948) 390-396.

702 [24] H.A. Barnes, H.A. Hutton, J.F. Walters, An Introduction to Rheology, Elsevier 703 Scientific Publishers New York, (1990).

704 [25] M.M. Cross, Rheology of non-Newtonian fluids a new equation for 705 pseudoplastic systems., Journal of Colloid Science., 20 (1965) 417-437. 
[26] D.S. Jones, D. Woolfson, A.F. Brown, Viscoelastic properties of bioadhesive, chlorhexidine- containing semi-solids for topical application to the oropharynx, Pharmaceutical Research, 15 (1998) 1131-1136.

[27] D.S. Jones, A.D. Woolfson, A.F. Brown, M.J. Oneill, Mucoadhesive, syringeable drug delivery systems for controlled application of metronidazole to the periodontal pocket: In vitro release kinetics, syringeability, mechanical and mucoadhesive properties, J. Control. Rel., 49 (1997) 71-79.

[28] D.S. Jones, D.A. Woolfson, A.F. Brown, Textural Analysis and Flow Rheometry of novel, bioadhesive antimicrobial oral gels., Pharmaceutical Research., 14 (1997b) 450-457.

[29] D.S. Jones, A.D. Woolfson, A.F. Brown, W.A. Coulter, C. McClelland, C.R. Irwin, Design, characterisation and preliminary clinical evaluation of a novel mucoadhesive topical formulation containing tetracycline for the treatment of periodontal disease, Journal of Controlled Release, 67 (2000) 357-368.

[30] D.S. Jones, M.S. Lawlor, A.D. Woolfson, Rheological and mucoadhesive characterization of polymeric systems composed of poly(methylvinylether-co-maleic anhydride) and poly(vinylpyrrolidone), designed as platforms for topical drug delivery, Journal of Pharmaceutical Sciences, 92 (2003) 995-1007.

[31] S. Dragan, M. Mihai, L. Ghimici, Viscometric study of poly(sodium 2-acrylamido2-methylpropanesulfonate) and two random copolymers., European Polymer Journal, 39 (2003) 1847-1854.

[32] R.M. Fuoss, U.P. Strauss, Polyelectrolytes. II. Poly-4-vinylpyridonium chloride and poly-4-vinyl-N-n-butylpyridonium bromide., Journal of Polymer Science, 3 (1948) 246-263.

[33] K.C. Tam, C. Tiu, Improved correlation for shear-dependent viscosity of polyelectrolyte solutions., Journal of Non-Newtonian Fluid Mechanics, 46 (1993) 275-288. 
733 [34] N. Mischenko, B. Denef, M.H.J. Koch, H. Reynaers, Influence of ionic effects on

734 the ordering and association phenomena in dilute and semidilute carrageenan 735 solutions. , International Journal of Biological Macromolecules, 19 (1996) 185-194.

736 [35] D. Fabri, J. Guan, A. Cesàro, Crystallisation and melting behaviour of poly (3737 hydroxybutyrate) in dilute solution: towards an understanding of physical gels. , 738 Thermochimica Acta, 321 (1998) 3-16.

739 [36] D. Khondkar, R. Tester, N. Hudson, J. Karkalas, J. Morrow, Rheological 740 behaviour of uncross-linked and cross-linked gelatinised waxy maize starch with 741 pectin gels., Food Hydrocolloids, , 21 (2007) 1296-1301.

742 [37] A.V. Dobrynin, M. Rubinstein, Theory of polyelectrolytes in solutions and at 743 surfaces. , Progress in Polymer Science, 30 (2005) 1049-1118.

744 [38] K.C. Tam, C. Tiu, Role of ionic species and valency on the steady shear 745 behavior of partially hydrolyzed polyacrylamide solutions., Colloid \& Polymer 746 Science, 268 (1990) 911-920.

747 [39] B.J. Dobraszczyk, M.P. Morgenstern, Rheology and the breadmaking process, 748 Journal of Cereal Science, 38 (2003) 229-245.

749 [40] P. Marco, J. Labanda, J. Llorens, The effects of some polyelectrolyte chemical 750 compositions on the rheological behaviour of kaolin suspensions., Powder 751 Technology, $148(2004) 1$.

752 [41] S. Baumgartner, M. Pavli, J. Kristl, Effect of calcium ions on the gelling and drug 753 release characteristics of xanthan matrix tablets., European Journal of 754 Pharmaceutics and Biopharmaceutics, 69 (2008) 698-707.

755 [42] S.M. Hanning, T. Yu, D.S. Jones, G.P. Andrews, J.A. Kieser, N.J. Medlicott, 756 Lecithin-based emulsions for potential use as saliva substitutes in patients with 757 xerostomia - viscoelastic properties, Int. J. Pharm., 456 (2013) 560-568.

758 [43] D.S. Jones, M.L. Bruschi, O. de Freitas, M.P.D. Gremiao, E.H.G. Lara, G.P. 759 Andrews, Rheological, mechanical and mucoadhesive properties of 
760

761

762

763

764

765

766

767

768

769

770

771

772

773

774

775

776

777

778

779

780

781

782

783

784

thermoresponsive, bioadhesive binary mixtures composed of poloxamer 407 and carbopol 974P designed as platforms for implantable drug delivery systems for use in the oral cavity, Int. J. Pharm., 372 (2009) 49-58.

[44] D.S. Jones, B.C.O. Muldoon, A.D. Woolfson, G.P. Andrews, F.D. Sanderson, Physicochemical characterization of bioactive polyacrylic acid organogels as potential antimicrobial implants for the buccal cavity, Biomacromolecules, 9 (2008) 624-633.

[45] V. Michailova, S. Titeva, R. Kotsilkova, E. Krusteva, E. Minkov, Influence of aqueous medium on viscoelastic properties of carboxylmethylcellulose sodium, hydroxypropylmethylcellulose, and thermally pre-gelatinized gels., Colloids and Surfaces, 149 (1999) 515-520.

[46] H. Hagerstrom, M. Paulsson, K. Edsman, Evaluation of mucoadhesion for two polyelectrolyte gels in simulated physiological conditions using a rheological method, European Journal of Pharmaceutical Sciences, 9 (2000) 301-309.

[47] S. Hsu, S. Lu, C. Huang, Viscoelastic changes of rice starch suspensions during gelatinisation., J. Food Sci., 65 (2000) 215-220.

[48] G.P. Andrews, S.P. Gorman, D.S. Jones, Rheological characterisation of primary and binary interactive bioadhesive gels composed of cellulose derivatives designed as ophthalmic viscosurgical devices, Biomaterials, 26 (2005) 571-580.

[49] H.H. Winter, F. Chambon, Analysis of Linear Viscoelasticity of a Crosslinking Polymer at the Gel Point., Journal of Rheology, 30 (1986) 367-382.

[50] C.M. Caramella, S. Rossi, F. Ferrari, M.C. Bonferoni, G. Sandri, Mucoadhesive and thermogelling systems for vaginal drug delivery, Adv. Drug Deliv. Rev., 92 (2015) $39-52$.

[51] T. Yu, K. Malcolm, D. Woolfson, D.S. Jones, G.P. Andrews, Vaginal gel drug delivery systems: understanding rheological characteristics and performance, Expert Opinion on Drug Delivery, 8 (2011) 1309-1322. 
787 [52] C.R. Irwin, K.C. McCullough, D.S. Jones, Chlorhexidine-containing 788 mucoadhesive polymeric compacts designed for use in the oral cavity: an 789 examination of their physical properties, in vitro/in vivo drug release properties and 790 clinical acceptability, J. Mater. Sci.-Mater. Med., 14 (2003) 825-832.

791 [53] D.S. Jones, C.R. Irwin, A.D. Woolfson, J. Djokic, V. Adams, Physiochemical 792 characterisation and preliminary in vivo efficacy of bioadhesive semisolid 793 formulations containing flurbiproen for the treatment of gingivitis, Journal of 794 Pharmaceutical Sciences, 88 (1999) 592-598.

795 [54] T. Yu, R.K. Malcolm, D.S. Jones, G.P. Andrews, Vaginal gel drug delivery 796 systems: understanding rheological characteristics and performance, Expert 797 Opinion on Drug Delivery, 8 (2011) 1309-1322.

798 [55] D.S. Jones, A.F. Brown, A.D. Woolfson, Rheological characterization of 799 bioadhesive, antimicrobial, semisolids designed for the treatment of periodontal 800 diseases: Transient and dynamic viscoelastic and continous shear analysis., 801 Journal of Pharmaceutical Sciences, 90 (2001) 1978-1990. 


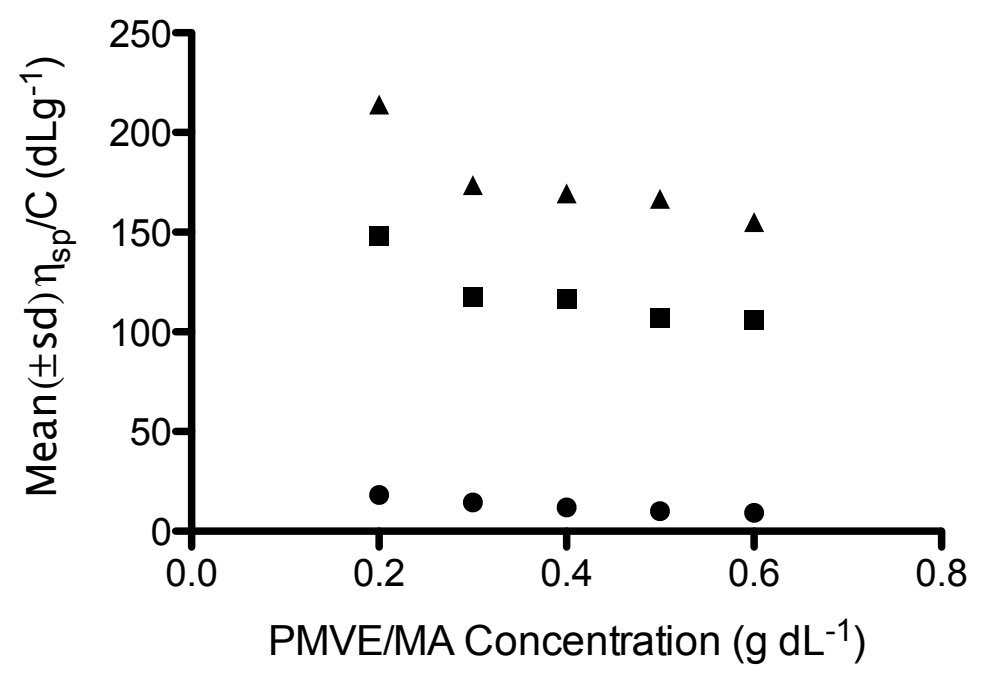

Figure 1a

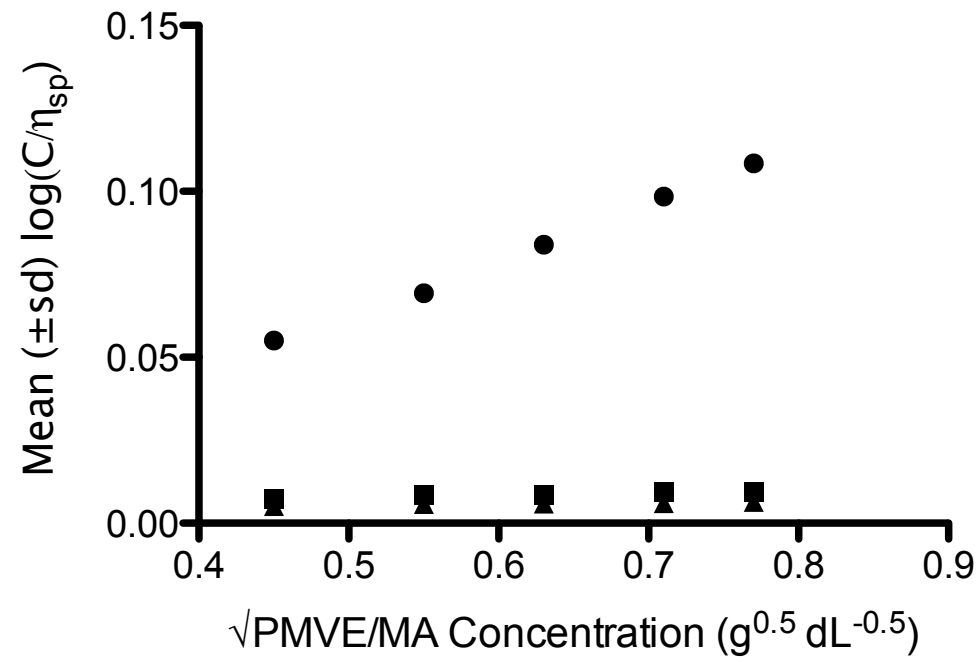

Figure 1b 


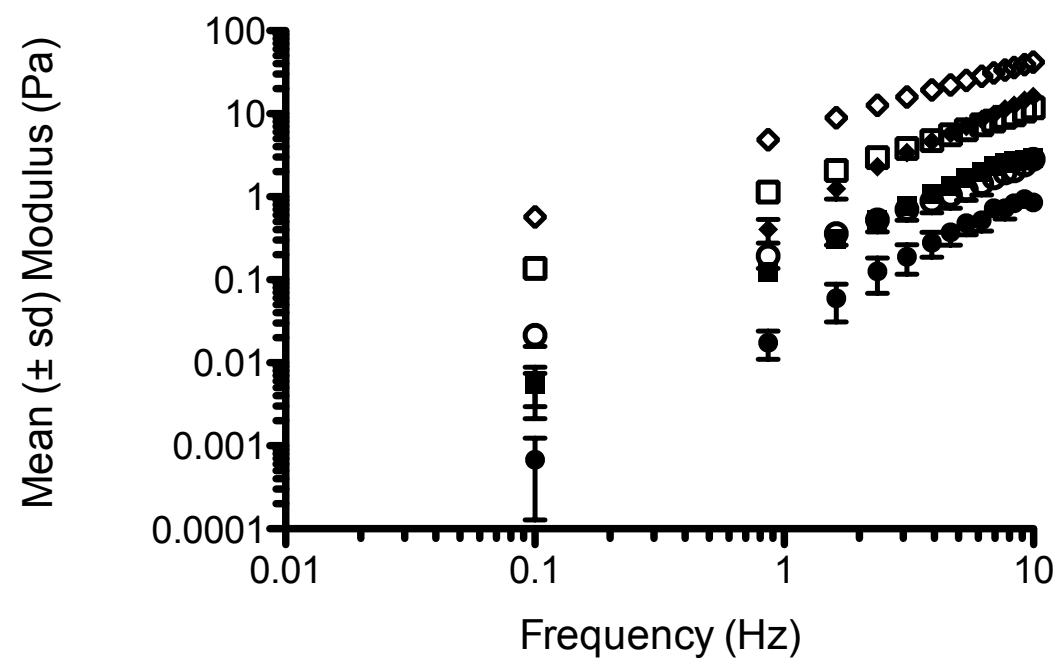

Figure 2(a)

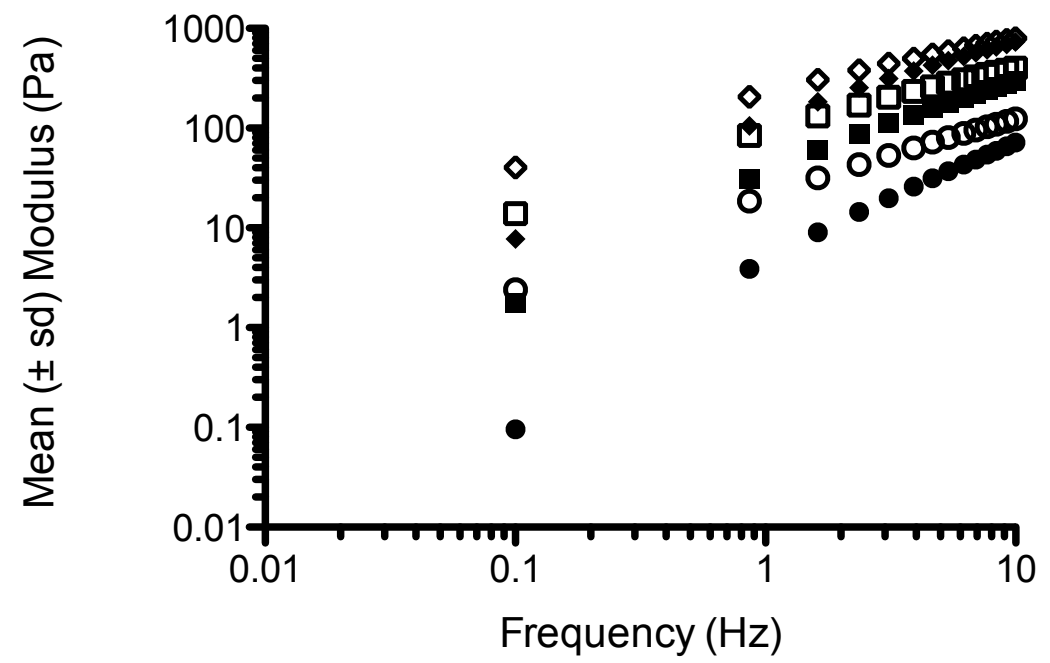

Figure 2(b) 


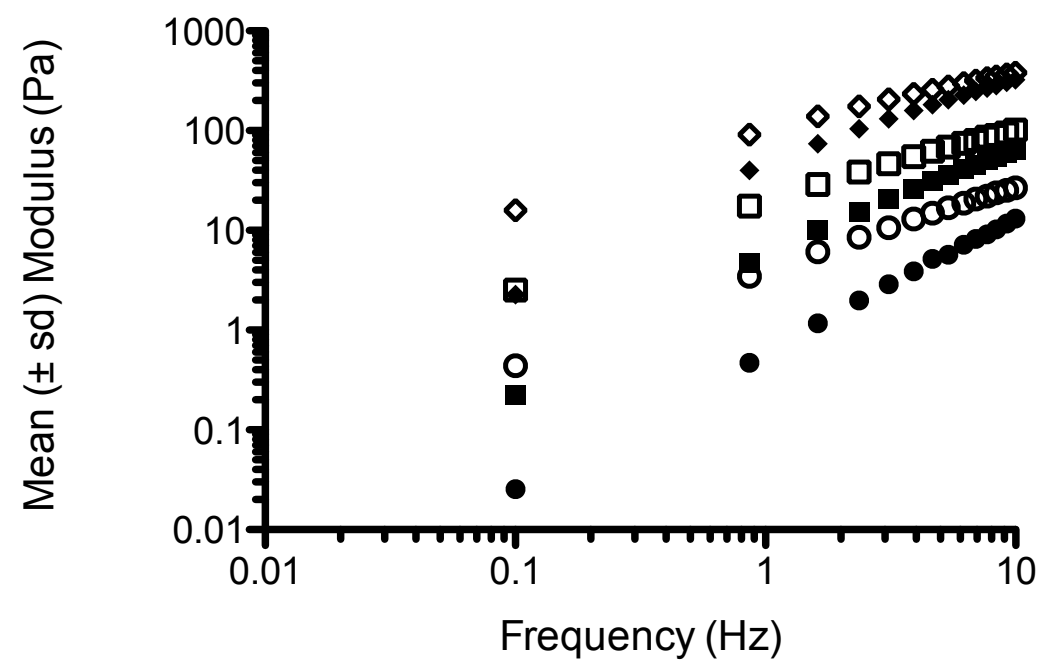

Figure 3a)

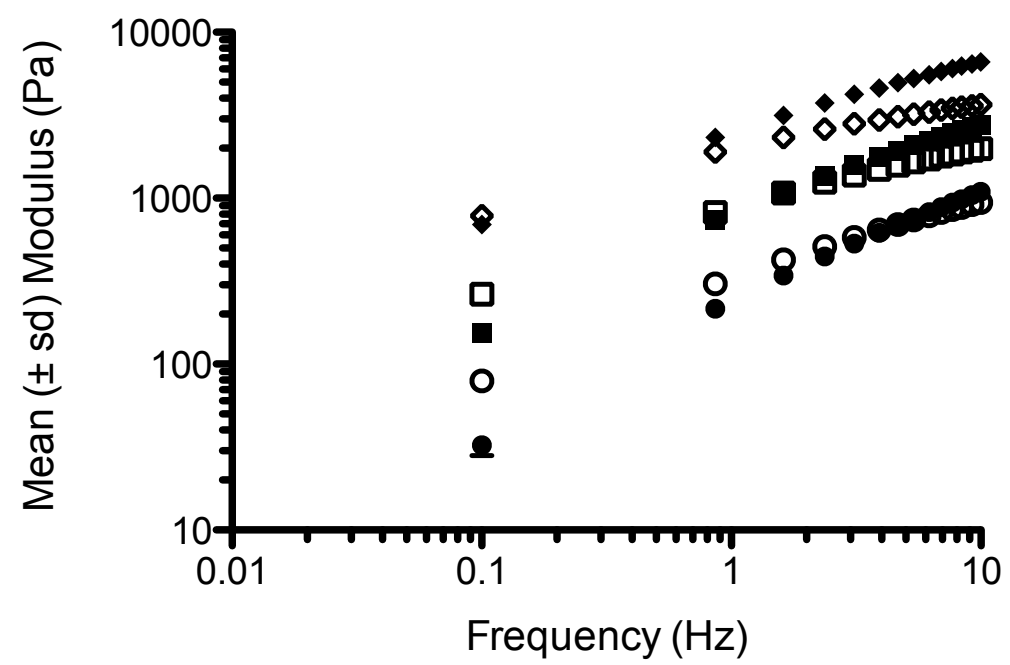

Figure 3(b) 


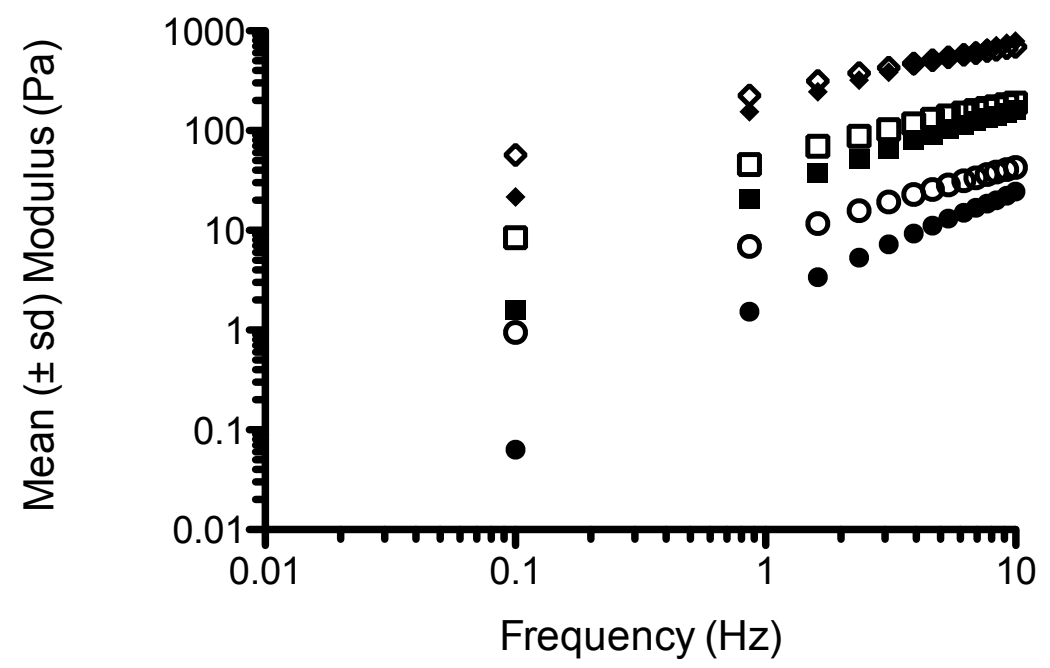

Figure 4(a)

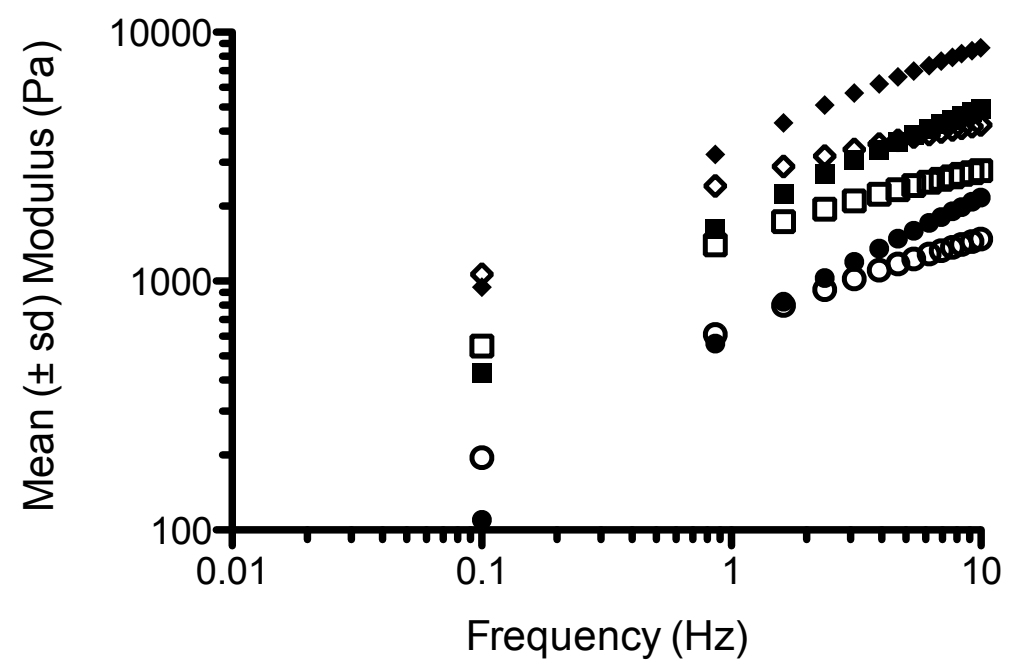

Figure 4(b) 
Table 1. The effects of polymer concentration, neutralising agent and oscillatory frequency on the loss tangent (tan $\delta$ ) and dynamic viscosity (n') of aqueous poly(methylvinyl ether-co-maleic acid) platforms

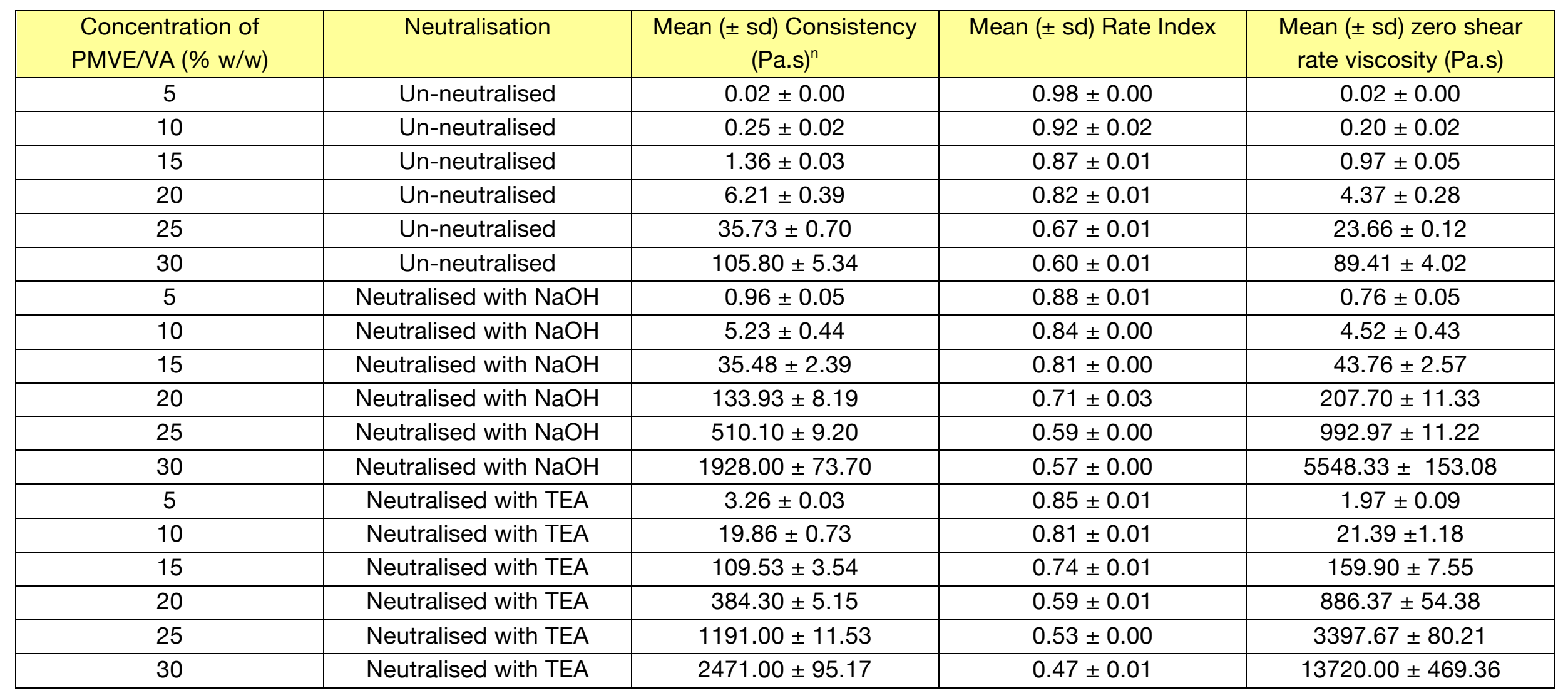


Table 2. The effects of polymer concentration, neutralising agent and oscillatory frequency on the loss tangent (tan $\delta$ ) and dynamic viscosity ( $\eta$ ') of aqueous poly(methylvinyl ether-co-maleic acid) platforms

\begin{tabular}{|c|c|c|c|c|c|c|c|}
\hline \multirow{3}{*}{$\begin{array}{c}\text { PMVE/MA } \\
\text { Concetration }\end{array}$} & \multirow{3}{*}{$\begin{array}{c}\text { Oscilatory } \\
\text { Frequency }(\mathrm{Hz})\end{array}$} & \multicolumn{6}{|c|}{ Mean ( \pm standard deviation) viscoelastic parameters } \\
\hline & & \multicolumn{2}{|c|}{ Unneutralised } & \multicolumn{2}{|c|}{ Neutralised (pH 7.4) with $\mathrm{NaOH}$} & \multicolumn{2}{|c|}{$\begin{array}{c}\text { Neutralised }(\mathrm{pH} 7.4) \text { with } \\
\text { Triethylamine }\end{array}$} \\
\hline & & $\tan \delta$ & n’ (Pa.s) & $\tan \delta$ & $\eta^{\prime}$ (Pa.s) & $\tan \delta$ & $\eta^{\prime}$ (Pa.s) \\
\hline \multirow[t]{3}{*}{5} & 2.37 & $\mathrm{NM}^{*}$ & $\mathrm{NM}^{*}$ & $4.19 \pm 0.28$ & $0.57 \pm 0.02$ & $2.94 \pm 0.05$ & $1.05 \pm 0.01$ \\
\hline & 5.39 & $\mathrm{NM}^{*}$ & $\mathrm{NM}^{*}$ & $2.82 \pm 0.20$ & $0.50 \pm 0.02$ & $2.18 \pm 0.03$ & $0.84 \pm 0.01$ \\
\hline & 9.99 & $\mathrm{NM}^{*}$ & $\mathrm{NM}^{*}$ & $2.01 \pm 0.20$ & $0.43 \pm 0.01$ & $1.75 \pm 0.10$ & $0.68 \pm 0.02$ \\
\hline \multirow[t]{3}{*}{10} & 2.37 & $\mathrm{NM}^{*}$ & $\mathrm{NM}^{*}$ & $2.54 \pm 0.07$ & $2.58 \pm 0.03$ & $1.68 \pm 0.01$ & $5.88 \pm 0.34$ \\
\hline & 5.39 & $\mathrm{NM}^{*}$ & $\mathrm{NM}^{*}$ & $1.93 \pm 0.03$ & $2.03 \pm 0.03$ & $1.37 \pm 0.01$ & $4.15 \pm 0.14$ \\
\hline & 9.99 & $\mathrm{NM}^{*}$ & $\mathrm{NM}^{*}$ & $1.60 \pm 0.04$ & $1.62 \pm 0.03$ & $1.18 \pm 0.01$ & $3.02 \pm 0.11$ \\
\hline \multirow[t]{3}{*}{15} & 2.37 & $5.60 \pm 0.70$ & $0.85 \pm 0.02$ & $1.68 \pm 0.01$ & $11.77 \pm 0.13$ & $1.17 \pm 0.00$ & $25.33 \pm 0.12$ \\
\hline & 5.39 & $3.57 \pm 0.12$ & $0.74 \pm 0.01$ & $1.37 \pm 0.01$ & $8.23 \pm 0.09$ & $0.99 \pm 0.00$ & $16.02 \pm 0.10$ \\
\hline & 9.99 & $2.62 \pm 0.07$ & $0.67 \pm 0.01$ & $1.18 \pm 0.01$ & $6.09 \pm 0.07$ & $0.88 \pm 0.00$ & $11.01 \pm 0.05$ \\
\hline \multirow[t]{3}{*}{20} & 2.37 & $3.00 \pm 0.13$ & $2.90 \pm 0.16$ & $1.15 \pm 0.04$ & $34.35 \pm 0.51$ & $0.90 \pm 0.00$ & $62.06 \pm 0.37$ \\
\hline & 5.39 & $2.17 \pm 0.08$ & $2.37 \pm 0.12$ & $0.98 \pm 0.03$ & $21.81 \pm 0.14$ & $0.77 \pm 0.00$ & $36.24 \pm 0.19$ \\
\hline & 9.99 & $1.73 \pm 0.07$ & $1.97 \pm 0.09$ & $0.86 \pm 0.02$ & $15.02 \pm 0.02$ & $0.68 \pm 0.00$ & $23.50 \pm 0.11$ \\
\hline \multirow[t]{3}{*}{25} & 2.37 & $1.95 \pm 0.01$ & $11.38 \pm 0.15$ & $0.92 \pm 0.00$ & $83.15 \pm 0.68$ & $0.72 \pm 0.00$ & $129.90 \pm 1.57$ \\
\hline & 5.39 & $1.57 \pm 0.01$ & $8.30 \pm 0.11$ & $0.79 \pm 0.00$ & $48.53 \pm 0.29$ & $0.63 \pm 0.00$ & $71.00 \pm 0.80$ \\
\hline & 9.99 & $1.35 \pm 0.01$ & $6.35 \pm 0.10$ & $0.71 \pm 0.00$ & $31.60 \pm 0.11$ & $0.56 \pm 0.00$ & $44.22 \pm 0.46$ \\
\hline \multirow[t]{3}{*}{30} & 2.37 & $1.51 \pm 0.02$ & $25.53 \pm 1.12$ & $0.70 \pm 0.01$ & $173.90 \pm 3.41$ & $0.62 \pm 0.01$ & $212.03 \pm 5.00$ \\
\hline & 5.39 & $1.25 \pm 0.02$ & $17.38 \pm 0.74$ & $0.61 \pm 0.01$ & $94.17 \pm 1.50$ & $0.54 \pm 0.01$ & $111.17 \pm 2.34$ \\
\hline & 9.99 & $1.09 \pm 0.01$ & $12.66 \pm 0.53$ & $0.55 \pm 0.01$ & $58.21 \pm 0.87$ & $0.49 \pm 0.01$ & $67.53 \pm 1.29$ \\
\hline
\end{tabular}

Not Measureable 
Table 3. The effects of polymer concentration, neutralising agent and oscillatory frequency on the loss tangent (tan $\delta$ ), dynamic viscosity $(n$ ') and mucoadhesion of aqueous poly(methylvinyl ether-co-maleic acid) platforms

\begin{tabular}{|c|c|c|c|c|c|}
\hline $\begin{array}{l}\text { PVME/MA } \\
\text { Concentration (\% } \\
\text { w/w) }\end{array}$ & Neutralisation & $\begin{array}{l}\text { Mean }( \pm \mathrm{sd}) \mathrm{Gel} \\
\text { Strength }(\mathrm{Pa})\end{array}$ & \begin{tabular}{|l|} 
Mean $( \pm \mathrm{sd})$ \\
Rheological \\
Exponent
\end{tabular} & $\begin{array}{l}\text { Crossover Frequency } \\
(\mathrm{Hz})\end{array}$ & $\begin{array}{l}\text { Mean }( \pm \mathrm{sd}) \\
\text { Mucoadhesive Bond } \\
\text { Strength }(\mathrm{N})\end{array}$ \\
\hline \multirow[t]{3}{*}{5} & Unneutralised & Not Measureable & Not Measureable & Not Observed ${ }^{*}$ & Not Measureable \\
\hline & $\mathrm{NaOH}$ & $0.61 \pm 0.13$ & $1.35 \pm 0.08$ & Not Observed* & Not Measureable \\
\hline & Triethylamine & $1.53 \pm 0.08$ & $1.27 \pm 0.03$ & Not Observed ${ }^{\star}$ & Not Measureable \\
\hline \multirow{3}{*}{10} & Unneutralised & Not Measureable & Not Measureable & Not Observed* & Not Measureable \\
\hline & $\mathrm{NaOH}$ & $4.62 \pm 0.34$ & $1.20 \pm 0.03$ & Not Observed ${ }^{\star}$ & Not Measureable \\
\hline & Triethylamine & $19.42 \pm 0.88$ & $0.98 \pm 0.00$ & Not Observed ${ }^{\star}$ & Not Measureable \\
\hline 15 & Triethylamine & $150.14 \pm 0.72$ & $0.76 \pm 0.00$ & $5.18 \pm 0.03$ & $0.70 \pm 0.04$ \\
\hline \multirow[t]{3}{*}{20} & Unneutralised & $3.50 \pm 0.37$ & $1.40 \pm 0.02$ & Not Observed* & Not Measureable \\
\hline & $\mathrm{NaOH}$ & $213.10 \pm 15.12$ & $0.75 \pm 0.02$ & $5.12 \pm 0.12$ & $0.70 \pm 0.03$ \\
\hline & Triethylamine & $547.52 \pm 4.70$ & $0.63 \pm 0.00$ & $1.34 \pm 0.02$ & $0.85 \pm 0.04$ \\
\hline \multirow[t]{2}{*}{25} & Unneutralised & $28.86 \pm 0.70$ & $1.08 \pm 0.01$ & Not Observed* & $0.12 \pm 0.01$ \\
\hline & $\mathrm{NaOH}$ & $732.59 \pm 10.26$ & $0.62 \pm 0.00$ & $1.48 \pm 0.03$ & $1.02 \pm 0.05$ \\
\hline
\end{tabular}

Not observed over the frequency range studied 